culture is concerned. Further, the climate of the Upper Palæolithic would appear not to have been uniform throughout its duration. It was cold in late Mousterian and Perigordian I, glacial in Aurignacian I, and so continuing up to the beginning of Solutrean, when it became milder. It continued to be milder throughout that period and in Magdalenian I-V. It was glacial in Magdalenian V and VI, and milder to temperate from Magdalenian through Azilian, Tardenoisian and neolithic.

\title{
Non-Destructive Testing
}

$\mathrm{U}^{\mathrm{N}}$ NER the auspices of the Institution of Electrical Engineers, a whole-day discussion was held on non-destructive testing on November 25. Seven introductory papers were arranged for and printed by a new association-the Joint Committee on Materials and their Testing.

The first paper was by Dr. A. P. M. Fleming and Mr. B. G. Churcher, and discussed electrical and magnetic methods. Seeing that modern physics has arrived at the conclusion that fundamentally all matter and all physical phenomena are electrical manifestations, and that electrical and other forms of energy have long been a matter of common experience, it is natural that electrical and magnetic methods of testing materials should be in everyday use. The authors divide these methods into three classes. In the first are included the methods used for measuring the intrinsic electrical and magnetic properties of materials ; in the second, the methods devised for the assessment or detection of a nonelectrical or non-magnetic property or condition by means of electrical or magnetic effects in a material ; finally, they describe the methods in which electricity or magnetism is used indirectly or incidentally in the assessment of a non-electrical or non-magnetic property of a material. In this latter class are included the measurements of dimensions, velocity, acceleration, fluid flow, pressure, temperature, illumination, etc. As these are not methods of testing materials, they have as a rule only been touched upon, but the modern methods of considering the thermal emissivity of surfaces, the specific heats of liquids and solids and the thermal resistivity of materials are specially mentioned. The greatest stress is laid on testing the magnetic properties of ferro-magnetic materials at high and low frequencies, as a knowledge of these is essential to the electrical industry. Various methods are described for detecting flaws or cracks in steel by means of a magnetic powder or by tracing out the lines of force at the surface by a small compass needle.

The second paper was by Dr. R. Berthold (Germany), who describes magnetic and electric devices for bridging the gaps left and overcoming some of the disadvantages which occur with X-ray and radium (gamma radiation) testing. He shows how the magnetic powder can be employed for detecting flaws in castings, worked objects, joints in metals, etc. In these cases the metals tested must be very carefully demagnetized after the test, particularly those to be used in aircraft.

In a paper by Dr. V. E. Pullen, who was the first to start testing metallic structures by X-rays at Woolwich twenty-two years ago, it is stated that radiological testing is incomplete without the use of complementary methods which usually become apparent in the course of the investigation. Illustrations are given of some of the elaborate apparatus used at
Woolwich and of the radiographs that can be obtained by their use. The paper by J. E. de Graaf (Holland) describes industrial radiography as now practised on the continent of Europe. Mobile apparatus is often used in this work. The necessary apparatus is transported in a motor vehicle which houses also the dark room and accessories. About sixteen such installa. tions are in operation on the Continent. There are one or two in Belgium, one in the Netherlands and about thirteen in Germany. The staff per car is composed of two or three men skilled in photographic technique. The results are interpreted by experts, who generally belong to a central body so as to ensure that a uniform standard is maintained.

Dr. Dorey gave an account of acoustic and general methods of non-destructive testing. Perhaps the oldest acoustic method of testing is that of listening to the sound produced by giving an article a sharp blow. It is instinctive on the part of the engineer who doubts the soundness of an article to give it a tap and listen for the ring. The production of a pure note corresponding to the natural frequency of vibration of the article may be taken as evidence that the article is sound and free from serious defects. A refinement of this method has recently been effected by the use of an ordinary medical stethoscope. For the testing of structural welds, a rubber cap is fitted over the searching end of the stethoscope, which is then placed against the welded plate whilst the weld under examination is tapped with a hammer. A high-pitched reedy sound occurring in the primary period of sound caused by the hammer blow indicates the presence of defects in the weld. So far this method has not been very successfully developed in Great Britain.

One of the most interesting and valuable methods of non-destructive testing has been in the design of objective noise meters. This work has been carried out in the National Physical Laboratory. The instruments are of the microphone-amplifier-meter type which have been adjusted for measuring the equivalent loudness of noise. Architects and building contractors now pay great attention to the acoustic properties of the materials used for walls, ceilings and floors. The tests are usually carried out by reverberation methods, and the sound-absorption coefficients are calculated from the period of reverberation of the chamber. Hydraulic tests are widely used in industry for proof-testing of pipes and hollow containers.

Dr. F. Förster and Prof. W. Köster (Germany) described a new apparatus for measuring the modulus of elasticity and the damping capacity of a material. They point out that the damping and the modulus of elasticity are quantities which, in contrast to many other technical values, possess an exact physical meaning. 
Messrs. H. H. Lester, R. L. Sandford and N. L Moehel, at the request of the American Society for Testing Materials, jointly undertook to write an account of non-destructive testing as practised in the United States. Radiographic methods are widely used in the States. Pressure-vessel manufacturers use fifty-seven installations, and there are thirty-one installations for various other applications. The American Society of Mechanical Engineers has greatly helped boiler-makers by constructing the A.S.M.E. Boiler Construction Code of definite standards of soundness to which manufacturers have to build. Porosity conditions are defined by pictures. Rejectable defects such as cracks and unfused regions are specifically designated and limits of toleration are established for slag inclusions. In the paper emphasis has been given to practical applications and to technological research of direct bearing on industrial practice. In conclusion. methods and regulations for testing porcelain and glass are given. All high-voltage porcelain parts designed for service above 6.6 kilovolts are given a 'routine' flash-over test. In addition, routine mechanical tests are made on all suspension insulators. The Polaroid Corporation has recently developed a glass strain detector built for the routine inspection of glass articles during the process of manufacture.

\section{Rothamsted Experimental Station}

\section{$\mathrm{T}$} HE Rothamsted Report for 1937* contains the results of experiments carried out at that Station during the year, and of crop trials undertaken at Woburn, and at a number of commercial farms, extending over a large area. Short accounts of the work of some of the departments of the Station are included, and also an extended summary of the research carried out in the Plant Pathology Department since its formation twenty years ago.

The experiments with chalk, discussed in this report, are of great interest because of the Government subsidy for the use of various forms of lime. Although liming is such an old practice, and although a large number of field trials have been carried out on the subject, there is a lack of precise knowledge on many aspects of the problem. Thus, it is often said that magnesium limestones are detrimental; but experiments planned at Rothamsted, and carried out in various parts of Britain, have given no evidence of this. The residual value of chalk has also been investigated and distinct improvements were obvious in crops some years after application; on an acid, sandy soil, for example, there is little sign of the effect of the dressing of lime disappearing after six seasons of eropping.

In a country with large numbers of live-stock, as in Great Britain, the conservation and utilization of farmyard manure is an important consideration, and many aspects of these problems have been under investigation at Rothamsted from its early days. In the 1937 report, the results of the early trials, which started in 1852, are dealt with briefly as a preliminary to the consideration of the more modern work. The earlier, long-period experiments showed that farmyard manure could give yields as high as those given by the best combination of artificial manures, and that it had considerable cumulative effects; in one instance, the increases in yield were considerable sixty-five years after the last application of dung. A number of modern, replicated experiments show that the response in potatoes averaged $2 \cdot 1$ tons per acre, and, in sugar beet, $1 \cdot 3$ tons per acre at Rothamsted. The increase resulting from 10 tons of farmyard manure was about equivalent to that from 2 cwt. of

- Rothamsted Experimental Station; Lawes Agricultural Trust. Report for 1937. Pp. 225. (Harpenden: Rothamsted Experimental Station, 1937.) 28. $6 d$. sulphate of ammonia. Experiments were also carried out to investigate the effects, on the yields of potatoes, and of sugar beet, of different methods and times of application of farmyard manure. With both crops, late application was superior to the earlier dressing. With potatoes, the application of the manure in the rows, at planting time in the spring, gave an increase of between one and two tons per acre more than when it was ploughed in in autumn. Finally, a number of experiments were undertaken to find whether artificials may be profitably applied on land that is also being dunged. The responses to sulphate of ammonia were increased in the presence of dung, while, with sulphate of potash, there was a small decrease.

An important aspect of the organized schemes of manuring experiments consists in the accumulation, by the Chemistry Department, of data which may make it possible to predict the fertilizer requirements of soils from their chemical analyses and textures. In 1936 and 1937, sugar beet gave much larger responses than in the three preceding dry seasons, and there was an opportunity of testing laboratory methods in this respect. The amount of inorganic nitrogen, obtained in the soil after incubation, gave a good degree of correlation with responses to sulphate of ammonia, while, with phosphoric acid, the fraction soluble in acetic acid corresponded to responses from superphosphate. It is unnecessary to emphasize the importance of this line of work at Rothamsted, as it will not only assist the individual agricultural adviser, but will also greatly increase the amount of useful information that can be obtained from soil surveys.

A note of this brevity cannot do more than mention the work of the Plant Pathology Department, summarized in this report. Among the important contributions from this laboratory must be cited the discovery of the 'green wart' method of infecting potatoes with wart disease ; this enables susceptibility or immunity to be determined within as many weeks as had hitherto required years. The investigations in this laboratory into the fundamental nature of virus diseases were extended after the Imperial Agricultural Conference of 1927, and the problem of the ultimate nature of these diseases is tackled from many angles. In one study, for example, it has been 